Laboratorio de Arte, 7-1994 http://dx.doi.org/10.12795/LA.1994.i07.21

\title{
LA MARCA DE LA CIUDAD DE CARMONA. NUEVA APORTACIÓN AL CATÁLOGO DE MARCAS DE LA PLATERÍA ESPAÑOLA.
}

\author{
por Marfa Jesús Mejfas Álvarez
}

El Arte de la Platería en Carmona, ciudad de la provincia de Sevilla distante a unos 30 kilómetros de la capital, parece no tener una actividad propia muy fuerte a lo largo de los siglos, como así lo demuestran las escasas noticias que nos suministra la serie documental de Actas Capitulares, y en general, los fondos históricos del Archivo Municipal y de Protocolos de dicha localidad.

Los pocos plateros activos en Carmona se organizaban dentro de un gremio, institucionalizado, creemos que en pleno siglo XVII, adquiriendo su momento de mayor auge en la primera mitad del siglo XVIII. Este leve desarrollo del gremio de plateros carmonense se debe, en gran medida, a la proximidad de Carmona con Sevilla cuyo gremio de plateros ejercía gran fuerza e influencia sobre los centros de población más cercanos, bloqueando todo intento de independencia y autogobierno.

Durante el siglo XVII es cuando empezamos a tener noticias documentales sobre el gremio carmonense. No hemos localizado ningún nombramiento de fiel contraste pero debió existir esta figura que se encargaba de vigilar el cumplimiento de la ley en lo referente a pesas y medidas de metales preciosos, pues en el Cabildo Municipal de 26 de septiembre de 1672 hallamos una petición de Francisco de Godoy, platero que se autodenomina contraste ${ }^{1}$. Tampoco hemos hallado nombramientos de alcaldes examinadores, pero de hecho existían ya que en el siglo XVII comienzan a realizarse los exámenes de maestría siendo el más antiguo del que disponemos en el Archivo Municipal de $1698^{2}$.

El examen, al no existir Congregación en Carmona, dependía del Cabildo de la ciudad, supervisado por el corregidor que era quien convocaba a los alcaldes examinadores. A pesar de la limitación que supone la falta de documentación al

1. Archivo Municipal de Carmona (A.M.C.). Libro 95, Actas capitulares, año 1672. S/f.

2. A.M.C. Legajo 676, años 1619-1710; s/f. Expediente de exámen de platero de Antonio de Luna. 
respecto, podemos afirmar que el gremio carmonense no poseía sistematización en su funcionamiento, quizás fruto de la escasa actividad de la que venimos hablando y del recortado número de miembros con el que debía contar.

En el siglo XVIII el gremio va adquiriendo más fuerza como lo demuestran el mayor número de noticias sobre plateros que nos facilitan las Actas Capitulares asi como el elevado número de expedientes de exámenes de maestría que se conservan de el Archivo Municipal carmonense ${ }^{3}$.

El auge del gremio en el siglo XVIII está protagonizado por dos familias: los LUNA y los GAMEZ. Sus cabezas son los plateros sevillanos, Antonio de Luna y Fernando de Gámez, que se examinan en Carmona en 1698 y 1700, respectivamente, y que con posterioridad fijan sus residencias en esta ciudad.

La escasa actividad del gremio hasta entrar el siglo XVIII se manifiesta en que Carmona no poseía marca de localidad, mientras que en otras ciudades de similares caracteres socio-económicos, como puede ser el caso de Ecija ${ }^{4}$, era ya habitual desde el siglo XVII.

En Carmona no será hasta el 1 de marzo de 1715 cuando el Cabildo de la ciudad decida mandar a ejecutar una efigie de las armas de la ciudad para que le sirviera como impronta ${ }^{5}$, ya que carecía de ésta. Esta decisión se toma tras el recibo de una Real Provisión fechada en Madrid a 30 de enero de 1715, en la que se ordenaba el cumplimiento de la normativa vigente que establecía que cada ciudad o villa tuviera su propia marca.

Desde esta fecha posee Carmona marca de localidad, basada en el escudo de la misma, que consiste en una estrella o lucero (Figura $n^{\circ} 1$ ). Marca que no hemos encontrado estampada en ninguna pieza de las que hoy se conservan en las iglesias y conventos carmonenses, y que nosotros mismos hemos catalogado y estudiado en nuestra tesis doctoral ${ }^{6}$. Esto no nos debe llevar a pensar que la marca local no se llegara estampar nunca, sólo que hasta el momento no se han localizado piezas con esta impronta, hecho que debe sugerir a los estudiosos del Arte de la Platería una revisión de aquellas marcas catalogadas como no identificadas, y una mayor atención a las posibles catalogaciones futuras.

3. A.M.C. Legajo 676, años 1619-1710;

Legajo 678, años 1731-1750;

Legajo 679, años 1751-1770;

Legajo 681, años 1783-1795.

4. Cfr. GRACIA LEON,G.: El Gremio de plateros de Ecija. Aspectos documentales. Sevilla 1985. Tesis de licenciatura inédita. Pp. 91-93.

5. A.M.C. Libro 138, Actas Capitulares, año 1715. Véase apéndice documental, documento $n^{\circ} 1$.

6. Véase: MEJIAS ALVAREZ,M.J.: Orfebrería Religiosa en Carmona (Siglos XV-XIX). Sevilla 1993. Tesis doctoral inédita. 


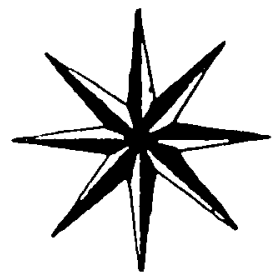

\author{
Figura $\mathrm{n}^{\circ} 1$. \\ Marca de la \\ ciudad de \\ Carmona.
}

Las marcas de los plateros carmonenses que hemos podido catalogar, tales como la de Francisco de Gámez (GAMEZ), vecino y residente en Carmona y examinado en esta localidad en $1784^{7}$, la de José Adrián Camacho (CAMACHO), platero vecino y residente también de Carmona pero examinado en Sevilla en $1771^{8}$, la de José Escamilla y Márquez (ESCANILLA), vecino de la ciudad de Carmona en $1802^{9}$, y la de Francisco Blanco (BLANCO), platero residente en Carmona pero que superó su prueba de maestría en Sevilla en el año $1803^{10}$, se muestran siempre en solitario como es lo normal en las piezas realizadas en esta ciudad, en la que al parecer no se era demasiado exigente con el cumplimiento de la normativa que obligaba a estampar la marca de localidad y la de contraste junto a la del maestro platero.

Lo cierto es que, por ahora, la marca de la ciudad de Carmona no está atestiguada en ninguna obra, aunque si descrita en varios documentos. Dos documentos nos hablan de ella claramente: por un lado, el acuerdo del Cabildo Municipal de primero de marzo de 1715, al que ya hemos hecho referencia; y , por otro, una carta de los plateros de la ciudad dirigida a la Junta General de Comercio, fechada en $1771^{11}$.

Esta carta de los plateros Manuel Gámez y José de Luna que en nombre del gremio carmonense y dirigida a la Junta General de Comercio, confirmando su aceptación de las Ordenanzas de 1771 y por la que solicitan impresos para su distribución entre sus miembros, es el documento que no sólo mejor describe la marca de la ciudad, sino que además es el que con más detalle hace un balance de la situación del gremio para estas fechas.

A lo largo de la misiva, y de ahí su interés, hacen los plateros de Carmona un recorrido por el estado del gremio: recuerdan los reales privilegios para realizar los exámenes de maestría, facilitan el número de maestros plateros y oficiales que trabajan en ese momento en la ciudad, nueve en total, describen la marca de la ciudad y, por último, consideran el título IV de las citadas Ordenanzas de 1771 adaptables a su gremio.

7. A.M.C. Legajo 681, años 1783-1795.

8. SANZ SERRANO,M.J.: Antiguos Dibujos de la Platería Sevillana. Página 200.

A.M.C. Legajo 325. Padrones vecinales de 1780-1787. Padrón de 1780, collación de San Bartolomé.

9. A.M.C. Legajo 328. Padrones vecinales, padrón de 1802, collación de San Pedro.

10. SANZ SERRANO,M.J.: Opus cit. Página 203.

A.M.C. Legajos 326 y 327 , padrones vecinales de 1788-1794, y de 1795-1801, respectivamente.

11. A.M.C. Legajo 152. Sección Gobierno. Ver apéndice documental, documento $\mathrm{n}^{\circ} 2$. 


\section{APENDICE DOCUMENTAL.}

\section{Documento $\mathrm{n}^{\circ} 1$.}

1715, marzo, 1. Carmona.

Acuerdo del Cabildo Municipal sobre la ejecución de la marca propia de la ciudad y la obligación de estamparla en la piezas.

A.M.C. Libro 138, Actas Capitulares de 1715.S/f.

"En este Cavildo se hiso relacion a la ciudad de una Real probision de su magestad y señores de su Real y Supremo Consejo que por copia firmada del señor abad de Bibanco se a traydo aeste cavildo en birtud de auto frlseñor correxidor,su data en Madrid atreynta de henero pasado destte año de milsetteçientos y quinse ganada a pedimento de don Joseph Garçia Cavallero ensayador mayor deestos reinos y bisitador del oro y platta quese labra en las Reales Casas de Moneda platerias bariojas y tiradores por la qual se manda que los maestros plateros tengan marcas con que marquen las piesas de oro y platta que labraren y que estas serreconoscan por marcador exsaminado y aprobado quien en ellas fije su marca y asimismo que las ciudades villas o lugares hagan marca de sus harmas y asimismo se fijen en las piesas de platta que de nuebo lavrasen para que por este medio se benga enconozimiento del oficial lavorante del marcador que la aprueba y de la ciudad o lugar donde se hubieren fabricado y noçiendo la platta de ley tenga recurso los compradores contra el fabricante y ensayador y de lo demas que en dicha real provision se prebiene-.....---

Item y la ciudad aviendola oido acuerda que la obedese conttodo el respeto y benerasion devida y que por lo que asi toca se guarde cumpla y ejecute como su magestad lo manda alen su cumplimiento el señor del Juan Berrugo su procurador mayor haga ejecuttar una efigie de las armas desta ciudad para con ella marcar las piesas de plata y oro que por los platteros deesta ciudad de nuebo se fabricaren la qual pongan en poder del presente scribano de cavildo y este siempre en el mas antiguo que del fuere para el dicho efectto $=y$ asimismo el plomo que por dicha real probision se manda en que sean de estampar lasmarcas asi el ensayador que fuere como delos maestros plateros que ay depresente en esta ciudad y de los que en adelantte della binieren para que tenga entero cumplimiento lo prebenido y mandado en dicha real provision--------

$Y$ se acavo y firmo como sea costtumbre==

Olias Don Pedro Bravo Navarro Anttemi

Cristobal Manuel de la Milla escrivano del cavildo." 
Documento $\mathrm{n}^{\circ} 2$.

(1771).Carmona.

Carta de Manuel Gámez y José de Luna, maestros plateros, en su nombre y en el del gremio de plateros de Carmona al presidente de la Junta de Comercio, solicitando se le manden ejemplares de las Ordenanzas aprobadas por la Real General Junta de Comercio y Moneda fechadas el 10 de marzo de 1771.

\section{A.M.C. Sección Gobierno. Legajo 152.}

"Don Manuel Games y don Joseph de Luna vezinos desta ciudad y mestros del Arte de la Plateria della,por nosotros mismos y por los demas de nuestro mencionado Arte y gremio por quienes prestamos voz y cancion del grato y rato salimos a los autos de cumplimiento de la real resolusion de Su Magestad en que a consulta de la real General Junta de Comercio y Moneda se sirvio de aprovarlas Ordenanzas que aquella formo y le propuso para los Colegios o Gremios de Artifices Plateros,y decimos,que siendo poquisimas y seguras las facultades que esta MUY NOBLE Y LEAL Ciudad tiene por Reales antiguos privilegios para promover la aprovacion y ezenccion en Maestros de los Practicos e inteligentes en dicha Arte como en otros exercicios para cuyo uso y maniobras consultando a la Publica utilidad se requiere perfecta suficiencia en el operante corriendo en todo el reino con correspondiente valor y estimacion dichas aprovaciones y magisterios a consequiencia desto y de la entitativa substancia desta Poblacion,y sucrecido vezindario subsisten en ella muchos Gremios de maniobras, entre ellos el nuestro de dicha Arte de Plateria,que en el dia se compone entre maestros,y oficiales de continuo uso del de nueve Yndividuos,siendo consiguiente a lo espuesto la nominacion de Maestros en Veedores,y Examinadores,y obrandose hasta aqui con ladebida regulacion en quanto ha ocurrido teniendo cada Maestro su Marca oseñal propia para lo que maniobra,a lo que se le graba tambien la del Pueblo,que es el Lucero Blason de sus Armas,en estos terminos pues,aunque no tiene dicho Gremio,o Artistas desta Ciudad particular Ordenanza propia esta mui pronto a recevir y cumplir en la parte que le corresponde la referida confirmada por Su Magestad en lo que esta le es adaptable,y superiormente se manda,que hemos llegado a entender,que es lo dispuesto en el titulo quarto de la que en impreso se ha dirigido a Vuestra Señoria deseando a este proposito el competente numero de exemplares para la respectiva intiligencia y observancia de dichos individuos,y de los artistas que existan en los pueblos de la comprehension y tesoreria desta ciudad y como quiera que en lo expuesto hacemos quanto esta de nuestra parte y aspiramos con el mas vivo deseo a la mayor perfeccion de dichas nuestras maniobras,y que mas y mas adelante dicho nuestro Gremio $===$

Suplicamos a Vuestra Señoria que definiendo a la mejor subsistencia deste,se sirva de facilitarnos por el medio que sea correspondiente,y este prevenido dichos exemplares a cuyo costeo en la competente cantidad estamos prontos,como a dicha observancia de lo que de dicha Ordenanzas y titulo quarto es adaptable a nuestro Gremio,que todo es asi de hacer en Justicia que pedimos, haciendo el pedimento y representacion que mas conveniente nos sea,y aya lugar con potesta de lo necesario.

Licenciado don Joseph de los Reyes Mendoza. Manuel Games Joseph de Luna." 